presentation in 7. Electroencephalographic-only seizures occurred in 9 of 32 subjects (28\%) with continuous EEG monitoring. One-year and 2-year remote symptomatic seizure-free survival rates were $82 \%$ and $67 \%$, respectively. One-year and two-year epilepsy-free survival rates were $96 \%$ and $87 \%$, respectively. Elevated intracranial pressure requiring acute intervention was a risk factor for seizures after presentation $(\mathrm{P}=0.01)$, for remote symptomatic seizures $(\mathrm{P}=0.03)$, and epilepsy $(\mathrm{P}=0.04)$. Single remote symptomatic seizures occur in many, and epilepsy is estimated to develop in $13 \%$ patients at 2 years after ICH presentation. (Beslow LA, Abend NS, Gindville MC, et al. Pediatric intracerebral hemorrhage. Acute symptomatic seizures and epilepsy. JAMA Neurol 2013 Apr 1;70(4):448-54). (Respond: Beslow LA, Section of Child Neurology, Yale University, New Haven CT. E-mail: lauren.beslow@yale.edu).

COMMENT. Acute symptomatic seizures were defined as those occurring up to 7 days after the incident $\mathrm{ICH}$, and remote symptomatic seizures as occurring beyond 7 days from ICH presentation. An editorial points out that acute symptomatic seizures with ICH occur more frequently in children (60\%) than in adult reports (7\%-31\%) (Heyer GL, Roach ES. JAMA Neurology 2013 Apr 1;70(4):437).

Hemisphere specific motor control mechanisms in post-stroke rehabilitation.

Left hemisphere damage is associated with greater errors in movement direction of the contralateral limb while errors in movement extent are greatest after right hemisphere damage. The differential deficits induced by right or left hemisphere lesions must be considered during post-stroke rehabilitation. (Mani S et al. Brain 2013 Apr;136(Pt 4):1288-303).

\title{
RISK FACTORS FOR ARACHNOID CYST HEMORRHAGE
}

Neurosurgeons at Primary Children's Medical Center, University of Utah, Salt Lake City, evaluated factors that are associated with rupture of arachnoid cysts (intracystic hemorrhage, subdural hematoma, or adjacent subdural hygroma) in children with previously asymptomatic arachnoid cysts. Two unruptured nonhemorrhagic controls were matched to each case. A total of 309 patients with treated and untreated arachnoid cysts were identified between 2005 and 2010, an institutional prevalence of 1.9\%. After exclusion of surgical cases, 232 remained in the study. Risk factors evaluated included arachnoid cyst size, recent head trauma, and altitude at residence. Fourteen cases $(6 \%)$ presented with either rupture or hemorrhage. Larger cyst size and diameter was significantly associated with cyst rupture/hemorrhage $(p<0.001)$. Recent history of trauma was also associated with outcome $(\mathrm{p}<0.01)$. Altitude was not a risk factor. Children with rupture/hemorrhage were more likely to present with headache or signs or symptoms of raised intracranial pressure, including midline shift. None suffered neurological sequelae. (Cress M, Kestle JRW, Holubkov R, Riva-Chambrin J. Risk factors for pediatric arachnoid cyst rupture/hemorrhage: A case-control study. Neurosurgery 2013 May;72(5):716-22). (Response: Jay Riva-Chambrin MD. E-mail: Jay.Riva-Cambrin@hsc.utah.edu).

COMMENT. Cyst size and recent head trauma are risk factors for cyst rupture. 